\title{
Corporeal Crafting: Tastes, Knowledges and Quality Protocols in British Cider-Making ${ }^{1}$
}

\author{
Emma-Jayne Abbots
}

\section{Introduction}

In this chapter I interrogate the ways in which craft cider makers utilise corporeal taste to construct their own normative framework of quality, in relation to both agricapitalism and initiatives that work to celebrate artisan production in the form of appellations of origin. My primary intention is to highlight the critical role the body and the senses play in the construction of knowledge about what constitutes a 'quality' cider and indicate the

\footnotetext{
1 This project was funded as part of an AHRC Care for the Future grant entitled Consuming Authenticities (AH/M006018/1). My thanks go to Elaine Forde and Hazel Thomas who were instrumental in the data collection, and to my project co-investigators, Deborah Toner, Anna Charalambidou, and Ana Martins. I am particularly indebted to all the cider producers who so generously gave their time and knowledge to the project. My gratitude is further extended to the editors and to the anonymous reviewer for their thoughtful and helpful comments on an earlier draft.
} 
tensions that emerge when such embodied and intuitive knowledge is abstracted and codified. In so doing, I show where bodies - both human and non-human - are located and made present in craft production processes, as well as the ways these are absented in makers' narratives of 'other' forms of production.

First, I discuss the elements that craft producers see as contributing to a quality craft cider, with an emphasis on manual labour, natural processes and minimal intervention. As such, I indicate the normative frameworks through which cider makers animate their ideas of a tasteful cider, which, in turn, enables the construction of their product and practice as craft in opposition to the tasteless products of agri-capitalism. This also draws attention to the vitality of non-human bodies and the unpredictable interactions between multiple substances. Secondly, I unpack how craft producers value these flavour inconsistencies that emerge from the interplays between human and non-human bodies, and tease out the disjuncture between their own markers of quality and the values that underpin appellation frameworks, such as Protected Geographical Indications (PGIs). Finally, I offer an exploration of how makers learn their craft through embodied practice and close with a reflection on the centrality of the senses craft cider making, as well as the interplays between bodies, taste and the reproduction of knowledge.

As I have argued elsewhere, the body - with some notable exceptions ${ }^{2}$ - is ironically rendered invisible in much

\footnotetext{
2 See, for example: Allison Hayes-Conroy and Jessica Hayes-Conroy, 'Taking Back Taste: Feminism, Food and Visceral Politics', Gender,
} 
of the literature on eating and drinking, which has tended to favour political economic analysis and symbolic meaning over affect, materialities and the senses. ${ }^{3}$ In parallel to this, a Foucauldian-inspired social constructionist perspective that draws attention to the ways in which bodies are subjected to and constituted by political dynamics and discourse has emerged ${ }^{4}$ which, while highlighting the fluid, fragmentary and socially embedded nature of bodies, has also paradoxically dropped the lived body from view. ${ }^{5}$ As Carolan notes, scholarship that claims to be about bodies rarely attends to 'actual bodies, in terms of how they think and feel' 6 and thereby 'misses the opportunity to add sentience and sensibility to our notions of self and person.?

In this chapter, I pay heed to the calls for a greater focus on embodiment and attend to the "bodiliness's of craft

Place \& Culture: A Journal of Feminist Geography, 15:5 (2008): 46173; Elspeth Probyn, Carnal Appetites: FoodSexIdentities, (London: Routledge, 2000); David Sutton, Remembrance of Repasts: An Anthropology of Food and Memory (Oxford: Berg, 2001).

${ }^{3}$ Emma-Jayne Abbots, The Agency of Eating: Mediation, Food and the Body (London: Bloomsbury, 2017).

${ }^{4}$ Judith Butler, Bodies That Matter: On the Discursive Limits of "Sex" (London: Routledge, 2003); Jan Wright, J. and Valerie Harwood, eds., Biopolitics and the 'Obesity Epidemic': Governing Bodies (New York: Routledge. 2009).

${ }^{5}$ Brian Turner, The Body and Society: Explorations in Social Theory, $2^{\text {nd }}$ edition. (London: Sage Publications, 1996), 28.

${ }^{6}$ Michael Carolan, Embodied Food Politics (Farnham: Ashgate, 2011), 9.

7 Thomas Csordas, 'Introduction: The Body as Representation and Being-in-the-World', in Embodiment and Experience: The Existential Ground of Culture and Self, ed. Thomas Csordas (Cambridge: Cambridge University Press 1994), 4.

${ }^{8}$ Ibid., 4. 
cider makers, while also situating embodied encounters within the broader political and economic dynamics of assessing, valuing and commodification. I align with scholarship that examines how subjective experiences produce politicised knowledges, and draw on the 'visceral geographies' perspective developed by Hayes-Conroy and Hayes-Conroy, which illustrates the interplays between the sensate body and political dynamics. ${ }^{9}$ In interrogating how social categories, such as race and gender, both shape and are shaped by the sensory experience of eating, they demonstrate the extent that 'social disenfranchisement and physical tastes both reinforce and resist each other ${ }^{10}$ and indicate the connections between body and society. Similarly, Carolan's study on embodied food politics elucidates how an individual body is directed - or 'tuned' in his words - towards industrial, highly processed foods and shows how seemingly individualised tastes are informed by wider political and economic frameworks. ${ }^{11}$ I build upon the foundations laid by these writers by illuminating how cider makers' embodied experiences facilitates the construction of the categories craft and craft maker, with a particular focus on the interplays between corporeal and social tastes.

This chapter is also informed by Bourdieu's seminal work on Distinction in which he examines the ways social tastes, while seemingly benign and natural aesthetic

${ }^{9}$ Hayes-Conroy and Hayes-Conroy, 'Taking Back Taste'.

${ }^{10}$ Jessica Hayes-Conroy, Savoring Alternative Food: School Gardens, Healthy Eating and Visceral Difference, (Abingdon: Routledge, 2014), 3.

${ }^{11}$ Carolan, Embodied Food Politics. 
judgements are instead socially inscribed through habitus, meaning embodied cultural capital, habits and practices. ${ }^{12}$ Bodies, then, are individual, social and political, ${ }^{13}$ and taste is both subjectively experienced and culturally informed. Bourdieu shows that tastemakers, in the form of cultural intermediaries, who manipulate the flow of knowledge between producers and consumers, are critical to this process as they set the agenda of what constitutes good taste and work from a position of legitimate information experts. ${ }^{14}$ Taste, acts as a mechanism for the reproduction of social difference, with the lower classes looking to emulate the 'good taste' set by groups of higher social standing. In situating such tastemakers within the burgeoning petite bourgeoisie professions of the 'cultural industries', Bourdieu, while highlighting class dynamics, however limits the political authority of knowledge to particular social actors who are positioned at the intersection of economy and society. ${ }^{15}$ In this chapter, I continue to look beyond such limitations as I explore the role that small producers, who do not appear at first glance to have the social status of cultural intermediaries, act as

${ }_{12}$ Pierre Bourdieu, Distinction: A Social Critique of the Judgement of Taste (New York and London: Routledge. 1994); The Logic of Practice, trans. R. Nice (Bloomington, IN, Stanford University Press, 1990).

${ }^{13}$ Nancy Scheper-Hughes and Margaret Lock, 'The Mindful Body: A Prolegomenon to Future Work in Medical Anthropology' Medical Anthropology Quarterly, 1:1 (1987) 6-41.

${ }_{14}$ Bourdieu, Distinction.

${ }^{15}$ Matthews, Julian and Jennifer Smith Maguire, 'Introduction: Thinking with Cultural Intermediaries', in The Cultural Intermediaries Reader, eds., Jennifer Smith Maguire and Julian Matthews (London: Sage, 2014) 1-12; see Abbots, The Agency of Eating. 
tastemakers in both senses of the word, despite seemingly having lower levels of economic and political capital than large-scale manufacturers and legal institutions.

\section{Introducing the Cider Makers}

My discussion is based on qualitative data collected from a number of craft cider-makers located across Wales and Herefordshire through a mixed-method approach, including focus group discussions and interviews, personal history collection, participatory mapping and participant observation. ${ }^{16}$ The subjects of my study can be classified as 'artisan' producers in that they produce less than 7,000 litres of cider a year, although, as I show below, factors beyond size and scale inform the construction of these makers' products and practices as 'craft'. Their own definitions of craft are not, however, uniform and a small number are uncomfortable with the term, preferring instead to focus on 'just being a maker of good cider', while others actively and passionately embrace the label. Nearly all the makers are relatively new entrants to the market and do not have a previous background in cider (outside of drinking it). Many started cider making as a hobby and have had to learn the necessary skills through trial and error, reading instruction manuals, talking to the craft cider community, which they find to be generally supportive to new entrants, and spending time with other makers who have mentored them.

${ }^{16}$ Due to commercial sensitivities, I do not identify any producer by personal or company name and direct quotations are therefore not attributed to named individuals. 
Contrary to the image that is commonly depicted in marketing narratives of cider, as seen in the advertisements of large-scale producers, the majority of the craft producers with whom I conducted research do not originate from a farming background and few have their own orchards. Instead, they rely heavily on forming relationships with other farmers, estate and orchard owners, and even individuals who have a couple of cider apple trees to source their raw ingredients, with one telling me how he could often be found driving around the neighbouring countryside in a hunt for cider apples. This reliance on friends and neighbours continues during harvest, when makers encourage others to help them pick the apples by hand and transport them. A sense of collectivism is hence evident in many makers' narratives, which often highlights how making cider is a lifestyle choice that enables them to live and work with friends and family in beautiful countryside. As one maker stated 'cider has given me a border collie and a great view'.

A number of distinctive themes and commonalities thereby emerge from my participants' narratives, not least that they are looking to create a quality product of which they are proud, by working with nature and the community. This is not to state that the makers are not commercially aware, but rather to explain that economic gain, as I elucidate below, is not the primary motivating force. The makers should not be regarded as a homogenous group, however, as they come to cider making with a range of professional backgrounds, personal experiences and political and economic capital. Some, for example, still need to work in waged full- or part-time 
employment to economically survive, whilst others have retired from positions in engineering and medicine. A small number have significant landholdings and large properties, whereas others produce their cider in small makeshift garages and sheds. A few presses are handbuilt from scrap materials, but some makers are able to invest heavily in new technology. Many, especially those located in southwest Wales, have also recently moved into the area, not uncommonly from England and the southeast, whereas a small number define themselves as Welsh. There is not the scope nor space here to tease out these variances, but I do indicate differences of opinion and tensions when it is relevant in my account below.

\section{The Embodied Labour of Flavour}

One of the central tenets of many a craft maker's narrative about the ingredients required for a good tasting cider is manual labour, with a number emphasising that it is in such embodied practices that craft can be located. They talked at length about the care and attention required to produce a flavourful cider: from handpicking the apples to hand-washing them in cold water to inspecting each apple individually for blemishes to pressing the pomace, makers all stressed the bodily presence and physical work involved at each stage of the process. This was summarised neatly by one producer who responded to my question about what makes a craft cider by exclaiming 'a bad back!' - a flippant response perhaps, but one that points to the value of manual labour and the centrality of the human body in creating both a good cider and a good 
cider maker. Within such framings, the introduction of new technologies and interventions are unsurprisingly deemed problematic, insomuch as they detract from the taste of the end product. This is explicable, in part, by the value producers place on slowness, with one maker telling me that, although an increase in demand motivated them to invest in technology, they returned to more labourintensive methods as the quality declined. He explained:

... we decided to invest in a belt press. A huge great thing! It washed the apples, took the apples up a spiral tube, scratted them then took them through presses. ${ }^{17}$ It made the cider so fast that the quality of the cider went. There was too much sediment, we just didn't like it. Labour-wise the press saved us a lot of time but we've got rid of it. Now we have this lovely twin-screw press. Very old, a lot of work, we don't make as much cider, but the quality is better.

Similarly, a number of producers were sceptical about a neighbouring maker who was embracing technology in the form of mechanised production lines, sharing with me that they thought his cider had become less flavoursome since he had adopted such measures. In the words of one maker, his cider has 'lost its oomph' - meaning the unidentifiable magic ingredient that elevates a cider from average to high quality that can only be discerned upon drinking and tasting. For his part, the maker who was readily adopting newer technologies argued it doesn't matter if it's wooden barrels or steel vats - it's still craft.

\footnotetext{
${ }^{17}$ Scratting refers to the breaking up of apples in order for them to enable them to be pressed for juice.
} 
They're just the tools for the job - the tools that you use', and located his skill in his innovation and mastery of the materials. For most, then, speed of production matters. Jackson and the CONANX Group state that 'most definitions of artisanal production stress its handmade and small-scale nature with minimal use of mechanization ${ }^{18}$ and cider makers are no different: they echo the established popular argument that slowness of production equates to care and quality, ${ }^{19}$ as well as scholarship on how the modernisation of the food system has triumphed over the constraints of time and space to produce cheap, low quality food. ${ }^{20}$

Inherent within these framings is the premise that technology, in the form of industrial equipment, acts to alienate the producer from their end product. ${ }^{21}$ Yet, as West points out, what is deemed technological and mechanised is relative and problematic, with objects that were once regarded as industrial now being seen as museum pieces. ${ }^{22}$ This insight holds true for cider production, which

18 Peter Jackson and the CONANX Group, Food Words: Essays in Culinary Culture (London: Bloomsbury 2013), 27.

19 See, for example, Carlo Petrini, Slow Food: The Case for Taste (New York: Columbia University Press, 2001).

20 Sidney Mintz 'Food at Moderate Speeds', in Fast Food/Slow Food: The Cultural Economy of the Global Food System, ed. Richard Wilk (Lanham, MD: Altamira, 2006) 3-11.

21 Karl Marx, Capital: An Abridged Edition (Oxford: Oxford University Press 1995 [1867]).

22 Harry West, 'Artisanal Foods and the Cultural Economy: Perspectives on Craft, Heritage, Authenticity and Reconnection', in Handbook of Food and Anthropology, eds., Jakob Klein and James Watson (London: Bloomsbury, 2016), 400. See also Heather Paxson, The Life of Cheese: Crafting Food and Value in America (Berkeley, CA: University of California Press, 2013). 
has witnessed an evolution in production technologies from immovable horse-powered stone presses to horsedrawn travelling presses to the 'antique' smaller screw presses some makers continue to use today. Producers commonly downplay their use of modern equipment in their biographies and even the most cursory of glances through their marketing materials will yield a significant number of images of antique presses. This could be seen as a cynical marketing ploy and, while makers are very aware that images conveying tradition and the rural idyll fit with consumer expectations, this is not the key factor in their narratives. Instead, they talk fondly and animatedly about their more aged equipment that requires the input of manual labour, and stress how this contributes to the taste of their cider and their practice as craft. This very embodied engagement with the tools of their craft forges a connection between the maker's body and their product, and the resulting cider thus becomes imbued with the essence of the maker, as well as the substances of the raw materials and tools.

\section{4. 'You should be able to taste the apples'}

Trade-offs often need to be made, however, as makers strike a balance between commercial viability, labour costs and availability, and the desire to produce a flavoursome product. These are negotiated through the idiom of taste and, although they are rarely able to narrate what lies behind any compromises in the manual labour process, the equation of speed with a loss of flavour plays a significant role. Mechanisation detracts from the desired 
apple-rich flavour, which is one of the key characteristics of a quality cider, and makers aspire to make a drink that is as natural as possible. This means there should be no added extras in the form of artificial yeasts, sulphites and sugar. As one explained, a good cider is 'a natural product' made by 'leaving nature to do its stuff for three months'. Another young maker took me through his production process step-by-step by focusing on the natural processes of fermentation and the release of pectin involved, and downplaying any additions he had made, such as enzymes that split the juice. He reflected that 'there are more natural ways of doing it' and expressed the ambition to get to that stage, concluding that makers have to 'guide [their] cider in the right direction'.

It is not just the makers, but also apples and other matter, then, that are doing the work of giving the cider flavour. Bennett draws our attention to this vitality of both animate and inanimate substances by examining the manner in which things have the agency to affect and produce effect in human and non-human bodies. ${ }^{23}$ Questioning anthropocentric treatments of objects as 'dead matter', she demonstrates how food acts upon the body to create different cognitive effects - effects that, for Mol, lie beyond the control of the consumer's body. ${ }^{24}$ In writing that ' $[\mathrm{o}]$ rganic and inorganic bodies, natural and cultural objects... are all affective', Bennett thereby inverts the assumption that it is humans that act upon

${ }^{23}$ Jane Bennett, Vibrant Matter: A Political Ecology of Things (Durham, NC: Duke University Press, 2010).

${ }^{24}$ Ibid: ix; Anne-Marie Mol, 'I Eat an Apple: On Theorizing Subjectivities', Subjectivity, 22 (2008) 28-37. 
things, invoking an Actor-Network Theory-inspired model to argue that agency is relational, distributed and produced through dynamic interactions between human and non-humans. ${ }^{25}$ As such, she challenges the binary between subject and object, and nature and society. Similarly, Goodman calls for an approach that accounts for the 'hybrid co-productions of natures-cultures' and reveals, through an analysis of episodic events such as food scares, the multiple actors that shape a food's network. ${ }^{26}$

Returning to cider, these arguments enable us to posit that the end product is a hybrid of nature and culture, with the non-human raw materials acting to produce taste as much as the human craft producer. Moreover, they also give us a route to explore ways in which apples and yeasts act upon and create affect and effect in the maker, just as much as the maker acts upon his raw materials in the process of production. ${ }^{27}$ Viewed through this lens, craft production becomes a collaboration of multiple bodies, rather than an imposition of the human body onto nature. Yet it takes time for such collaborations to occur: it cannot be rushed. Time and space are required to enable the slow fermentation, in the form of interac-

25 Bennett, Vibrant Matter, xii. See also Bruno Latour, Reassembling the Social: An Introduction to Actor Network Theory (Oxford: Oxford University Press, 2005).

${ }^{26}$ David Goodman, 'Agro-food Studies in the "Age of Ecology": Nature, Corporeality, Bio-Politics', Sociologia Ruralis, 39:1 (1999), 28.

${ }^{27}$ I use 'his' purposefully here as cider making is gendered and all my participants were men, although women are involved in the process but often in a supporting, marketing and administration role. There is not the scope to explore these dynamics in this paper. 
tions between the human and non-human entities of makers, apples, yeasts, tools and casks. It is in this process that the quality of taste emerges.

\section{Sweetness v. Dryness: Industrial v. Craft}

Makers' valorisations of manual labour, slowness and natural production processes further facilitate the construction of craft cider as diametrically opposed to the offerings of large-scale, globalised producers, which are regarded by makers as lacking in apple flavour and tasting only of sweetness and sugar. Sweetness is treated ambivalently - at best - in craft cider circles, with selfstyled 'purists' advocating a dry flavour and some makers looking to attain dryness to distinguish their craft. Not all makers agree with such judgements and the levels of sweetness in craft ciders are subject to some discussion, with a number opposing the 'purists' and acknowledging a trend towards sweetness that is, in the main, driven by the desires of the consumer, especially the younger market that have been introduced to cider by global drinks manufacturers. Such younger consumers are also deemed to have sweeter palates as a consequence of the wider trend of increasing sugar consumption and a number of more mature makers expressed a concern that this trend was influencing younger makers, who are also regarded as having less of a palate and preference for dryness. Generational differences aside, the theme that sweetness to the detriment of apples is antithetical to a good tasting cider, and also typical of the products largescale corporations, is evident. 
There is a broader ethical framework at play here in which the craft maker juxtaposes their labour, their care and attention to their product, their relationship to nature and their commercial motivation to the values of largescale manufacturers. One maker declared, 'people who murder their grannies or rob their children won't make craft cider - they make [Cider Brand]! Because they'll be out to get rich quick. This startling indictment points to the ways in which craft producers assert their distance from global corporations through their distinct economic and social values, and I was told on more than one occasion how a craft maker would throw a barrel of cider away if it was not of sufficient quality, despite the economic cost. Others had resisted offers from larger retailers, as having a product placed in a supermarket chain is regarded as a sign of compromised integrity. One maker even restricted the availability of his product to consumers in his home county, arguing that there was an attraction to only being able to obtain a product in its particular locale. 'Selling out' in the form of increasing the scale and speed of production and marketing to a wider consumer base is thus equated to a shift away from craft and, by extension, a watering down of apples and sweetening of taste.

These constructions of the self as crafter in relation to the large-scale aligns with scholarship of the heritage food sector that has highlighted the fluidity of the term 'artisanal' and demonstrated its contingency with agricapitalism. Paxson, for example, argues that the category of the artisanal is formulated and 'othered' in relation to the industrial and West writes that this comparison 'is essential to the ever-changing definitions of the artisanal, as 
the category makes sense only in relation to its constantly changing other.' ${ }^{28}$ I wish to extend this well-established argument by stressing the role that taste plays in formulating such otherness. Other non-craft ciders are too sweet because they are (understood to be) made predominantly from (imported) apple concentrate with added sugar by fast and careless processes, rather than with naturally fermented apples that are carefully guided. The bodies of the makers, as well as the whole bodies of apples, are thus rendered invisible in narratives of large-scale production whereas they are front and centre in craft cider. The products of agri-capitalism are inevitably tasteless in such constructions: as Jackson and the CONANX Group observe, industrially produced foods are commonly 'caricatured' as 'bland' and 'overly standardized.' 9

Craft cider makers thereby construct their own normative framework, in relation to agri-capitalism, through which notions of acceptable production processes and desired flavours are propounded and upheld. It is in the taste of the product, then, that the oft-invisible embodied production practices can be brought to the fore and the moral integrity of the producer unveiled. Using taste in this corporeal sense further enables makers to produce ideas of what constitutes taste in the Bourdieusian sense, as they work to distinguish their product - and their production means and values - from the industrial. They thus emerge as tastemakers in both senses of the

28 Paxson, The Life of Cheese; West, Artisanal Foods and the Cultural Economy, 409.

${ }^{29}$ Jackson and the CONANX Group, Food Words, 25. 
word, albeit to a relatively small audience of other producers, as they set the agenda of 'good taste' that derides the mass-market and associates bland, sweet cider with a less-discerning maker and consumer. Corporeal taste, as the manifestation of a maker's value system, provides a paradigm through which social tastes can be defined, assessed, and hierarchised.

\section{Valuing Inconsistency}

The construction of their own 'good tasting' cider in relation to the tasteless, mass-market products of agricapitalism continues in craft makers valuing inconsistency. As one maker surmised it sounds strange; you always want to keep the quality but inconsistency [of flavours]'. This further elucidates the ambivalence surrounding the one producer who was shifting to higher levels of mechanisation, as he also advocated an approach that looked to abstract and replicate taste profiles and was hence moving towards a more consistent product. Nonetheless, this maker was also keen to state that this process could never be foolproof and he emphasised how he could not account for the interactions between materials that take place once the cider is fermenting, noting that one of his ciders developed surprising pineapple undertones when developing in newly purchased barrels that had once held rum.

The value placed on inconsistency can be related back to how the makers regard their product and practice as closer to nature than that of the agri-capitalists. There is unpredictability in natural processes. West makes a 
parallel observation about artisan cheese makers, who see the variable characteristics of their cheese as a reflection of the ever-changing environmental factors in which it is made, and contrast this to standardised, 'less natural', products. ${ }^{30}$ This further points to the vitality of the nonhuman, which cannot be fully controlled, as Mol's observations on eating an apple show. ${ }^{31}$ She writes that prior to eating there are two discrete entities: the human body and the apple. Yet upon eating, the apple's body fragments and becomes incorporated into the eater's body, thus breaking down the barriers between object and subject: each blurs into the other. This process is not fully governed by the human eater, as the apple's substances work within the human body and engage with internal organs in unpredictable ways. Agency is thus dispersed with multiple bodies all acting upon each other in myriad ways. This is further illustrated by Bennett's account of fat in which she argues that, while the substance creates different cognitive states, it does not do so as mechanical causality, with predictable results. ${ }^{32}$ Rather, it should be seen as a process of emergent causality, meaning that different fats prompt different effects and affects in different bodies in different contexts.

In cider, the unpredictability of natural processes can also lead to innovation, as unintended and unexpected flavours, such as pineapple, emerge and makers explore the non-human bodies that interacted to do so. New

\footnotetext{
${ }^{30}$ West, Artisanal Foods and the Cultural Economy.

${ }_{31} \mathrm{Mol}$ I eat an apple.

32 Bennett, Vibrant Matter, 41-2.
} 
product lines are 'developed' in this manner, with one maker starting a line of vinegars and chutneys as a consequence of a batch of cider fermenting in unanticipated ways. This maker also produced an award-winning cider, but informed me that they could in no way replicate it, even if they so desired, because they were not sure how they produced it in the first instance. Such statements were proudly professed as they serve to reassert a maker's credentials as an artisan who is more concerned with making a good-tasting cider than garnering financial rewards and mass-market appeal. In contrast, the economic success of agri-capitalism is premised on the production of a consistent-tasting product. This consistency of flavour, regardless of geographical location, is, as Ritzer explains in his thesis on 'McDonaldization', the fundamental production rationality driving the expansion and economic success of globalised corporations that leads, in his rendering, to cultural homogenisation. ${ }^{33}$

Consistency also facilitates a mass-market experience that is seemingly placeless, as food becomes disembedded from its site of production and consumers disconnected from producers in both perception and lived experience. ${ }^{34}$ The sites and relations of food production are obscured as they grow in complexity. ${ }^{35}$ Even alternatives,

${ }^{33}$ George Ritzer, McDonaldization: The Reader, (Los Angeles, CA: Pine Forge Press. 2010).

${ }^{34}$ Moya Kneafsey et al., Reconnecting Consumers, Producers and Food: Exploring Alternatives, (Oxford: Berg, 2008).

35 Benjamin Coles, 'Placing Security: Food, Geographical Knowledge(s) and the Reproduction of Place(less-ness)' in Careful Eating: The Embodied Entanglements of Food and Care, eds., Emma-Jayne Abbots, Anna Lavis and Luci Attala (Farnham: Ashgate, 2015) 151-72. 
in the form of heritage products, organic foods and artisan production, serve to replicate such spatial and temporal relations, as they reproduce the hegemonic dynamics of agri-capitalism by constructing their offering in opposition to it. ${ }^{36}$ Needless to say, it is this very opposition to industrial food that craft cider makers value and look to create. They may be reinforcing industrial cider manufacturing by establishing an 'alternative' in relation to it, but (in)consistency - borne from a particular geographical locale and unpredictable materials, a visible site of production, and connections between human and nonhuman bodies - at least gives them a taste-based mechanism through which they can distinguish themselves and their product.

\section{Branding Place-based Food}

A tension further emerges when craft producers' celebration of inconsistency is placed alongside the normative frameworks of protected geographical indications (PGIs), which work to abstract, codify and scale the quality of a food stuff by emphasising its place-based particularities particularities which, as we have seen, are often unpredictable and inconsistent. As West explains, PGIs, along with protected designation of origin (PDOs), form part of a suite of appellations of origin and geographical indications that are regulated through a 'growing array of national laws and international treaties that sometimes

${ }^{36}$ Benjamin Coles, 'The Shocking Materialities and Temporalities of Agri-Capitalism, Gastronomica: The Journal of Critical Food Studies, 16:3 (2016): 5-11. 
reinforce and sometimes contradict one another.'37 Emerging from the formation of the European Union in 1992, PGI status relates to 'products for which the quality or characteristics are essentially or exclusively due to geographical conditions' and pertains to products that are partially prepared, produced and processed, in a traditional manner, in a specific, defined region. ${ }^{38}$ It therefore works to provide a counter to the seemingly 'placeless' and homogenised products of agri-capitalism by celebrating place-based connections and terroir. As such, it could be assumed that craft cider makers would value such a designation.

'Traditional Welsh Cider', which recently acquired PGI status, is described as:

cider made in Wales from first-pressed juice of cider apples from any indigenous and non-indigenous apple varieties grown in Wales to a traditional production method. Traditional Welsh Cider may be made from a blend or a single variety of first pressed apple juice. 'Traditional Welsh Cider' is made from $100 \%$ pure cider apple juice. ${ }^{39}$

${ }^{37}$ Harry West, 'Appellations and Indications of Origin, Terroir, and the Social Construction and Contestation of Place-Named Foods' in The Handbook of Food Research, eds., Anne Murcott, Warren Belasco and Peter Jackson (London: Bloomsbury 2013), 210.

38 Ibid. 227. This is in contrast to the more stringent PDO status, whereby a product must be entirely prepared, produced and processed in a determined geographical region using traditional methods.

39 Department of Environment, Food and Rural Affairs 'Protected food name: Traditional Welsh Cider https://www.gov.uk/government/publications/protected-food-name-welsh-cider, (accessed 11 November 2017), 2. 
Such a description appears to align neatly with the makers' own values, and the application was drawn up by the Welsh Perry and Cider Society in consultation with its members. Yet, a significant proportion of my participants was largely ambivalent about the designation and did not see it as means through which to enhance the value of their product. They tended to avoid the topic in discussions, and made it clear that they did not have an interest in it, nor regard it as relevant to discussions of craft and artisanal production. There were few strong feelings against appellation protocols, but there were no strong inclinations towards it either. In part, this apathy can be attributed to the practicalities of producing a cider from solely Welsh-grown apples, as a number of makers source their raw materials from across the border in England, in addition to the interpersonal relations within the cider community. But it also stems, I would suggest, from differing value systems and paradigms of distinction.

The disjuncture between craft makers and formalised paradigms of appellations of origin is documented in Cavanaugh's study of salami in Bergamo. ${ }^{40}$ She elucidates a process of commodification, reification, and appropriation, as a foodstuff that was once deeply entrenched in small-scale and domestic spaces, and hence laden with sociality, is extracted by large-scale producers and potentially regulated under Geographical Indication (GI) protections. As such, Cavanaugh argues, the product becomes less 'our salami' (salame nostrano) as it is

${ }^{40}$ Jillian Cavanaugh, 'Making Salami, Producing Bergamo: The Transformation of Value, Ethnos, 72:2 (2007): 149-72. 
increasingly abstracted from the community. A similar process of alienation and appropriation is further documented in West and Domingos's account of Serpa cheese in Portugal, which explores how small-scale producers, who have had to modernise their production practices to become commercially viable, were effectively excluded from a Slow Food Presidia that valued 'traditional' production processes - much like the wording of Traditional Welsh Cider's PGI description. ${ }^{41}$ Ironically, glossing over the historical social and economic inequities that motivated craft producers to change to less risk-laden production methods in the first instance, West and Domingos write that the Presidia sought to reify an idealised, historicised and codified form of making Serpa that was ultimately removed from the everyday realities of small-scale producers in the present. A picture thus emerges of actors with higher levels of economic, political and cultural capital - in the form of multinational corporations and political and community leaders - adopting place-based markers of quality in a manner that disenfranchises the voices of the very craft makers that such protocols and practices are designed to protect.

Processes of alienation from the small-scale notwithstanding, the extent that appellations of origin are markers of quality and reflections of traditional production practices have also been questioned. West also tells us that, in some contexts, appellation frameworks have

${ }^{41}$ Harry West and Nuno Domingos, 'Gourmandizing Poverty Food: The Serpa Cheese Slow Food Presidium', Journal of Agrarian Change, 12:1 (2012), 120-43. 
been appropriated by agri-capitalism and resulted in what some see as an 'erosion or abandonment of traditional methods in favour of more modern, more profitable ones. ${ }^{42}$ Likewise, Bowen and Zapata note that smaller producers of Mexican tequila were marginalised as larger producers used less ecologically sustainable methods, such as mono-cropping and pesticide use, in order to capitalise on the drink's PDO status. ${ }^{43}$

As Bowen and De Master observe, such processes of codification can threaten the diversity of traditional practices, as, in seeking to standardise the attributes of quality, they are unable to account for the dynamism and unpredictable nature of craft production - the very characteristics valued by cider makers. ${ }^{44}$ For them, quality, in terms of taste, cannot be placed on a scale, labelled or be made to fit within a set framework of regulations. Their end product is not only too unpredictable for such apparatus, but it's very quality - and by extension the identity of the maker - is based on its inconsistency and innovation. A disjuncture of value systems and normative frameworks of quality between craft makers and appellations protocols thereby emerges.

This is not to state that craft cider makers do not value tradition or place. On the contrary, they consistently celebrate historical continuities in practice, materials and

42 West, Artisanal Foods and the Cultural Economy, 420.

43 Sarah Bowen and Ana Valenzuela Zapata 'Geographical Indications, Terroir, and Socioeconomic and Ecological Sustainability: The Care of Tequila', Journal of Rural Studies, 25: 1(2009), 108-19.

44 Sarah Bowen and Kathryn De Master, 'New Rural Livelihoods or Museums of Production?: Quality Food Initiatives in Practice, Journal of Rural Studies, 27: 1(2011), 77. 
environment and are aware of the legacy on which they draw. Such continuities are not rendered static, however, but allow for a conception of tradition that is fluid and subject to change, in contrast to more reified frameworks. Nor I am arguing that cider makers do not have a normative framework or one that is any less prescriptive than other paradigms. They abstract, define and uphold quality and assess practices and products against such markers just as much as other framings. They just do so through a value system that does not align neatly with appellation protocols and regulatory frameworks.

\section{Embodied Knowledges}

The process of abstracting elements of cider, which are subjectively experienced through taste, into a quality framework, is not a process without its difficulties or tensions. It has been noted that artisan food producers commonly have 'an historical, experiential, and intuitive understanding' that comes from 'hands-on knowledge', and it is this quality that enables the association of artisanal food production with corporeal taste. ${ }^{45}$ The producers with whom I conducted my research were no different. Whilst some cidermaking knowledge was gained from reading instruction manuals and working and talking with other cider makers, much of their knowledge is acquired through trial and error and learning 'on the job'. This, as I have indicated above, can lead to expensive mistakes, as well as innovation, experi-

${ }^{45}$ Jackson and the CONANX Group, Food Words, 23-5. 
mentation and new product ranges. It also leads to the development of a palate through continuous drinking and tasting, through which the identification of different flavour elements is learnt, assessed and valued. Makers' bodies are, then, at the forefront of knowledge-making, with one maker telling me he tasted his cider every day while it was coming towards the end of the fermentation process in order to assess the optimum moment to bottle it. Similarly, another maker discouraged me from choosing his cider at a festival as it, to paraphrase him, 'just wasn't right and needed more time'. The cider, to my palate, was of a perfectly high quality, but the maker had the greater experiential knowledge of drinking his earlier ciders and those of other makers. His palate was, in the words of Carolan, 'tuned' through the continued sensory experience of tasting and assessing multiple ciders over the course of his career. ${ }^{46}$ Certain subjective flavour sensations are, then, ascribed to socially produced knowledge. ${ }^{47}$

This embodied practice of identifying and valuing the flavours that constitute a quality craft cider can be cast not only as the human body obtaining knowledge of material substances, but also, returning to Mol's apple, of those material substances acting upon the consuming body. Foods acquire bodies as much as bodies acquire foods, as human bodies are dialectically shaped by the non-human bodies acting upon them. ${ }^{48}$ This encounter of bodies does

\footnotetext{
46 Carolan, Embodied Food Politics.

47 Probyn, FoodSexIdentities.

48 Abbots, The Agency of Eating, 55
} 
not occur in isolation, however, but in dialogue with socially produced knowledge paradigms that distinguish and place value on embodied experiences and thus work to identify markers of quality. Such encounters between bodies, and between bodies and knowledge, (re)produces normative frameworks about desired (and undesired) tastes and attributes categories, such as sweet, dry and apple-rich in the context of cider, to the substance being tasted.

Yet, while cider makers can agree that a good-tasting cider contains the desired balance of valued flavours, how each maker experiences those characteristics can differ subjectively. This was particularly evident from the heated debates that took place during cider competitions, when makers blind-taste and judge a range of ciders but, at times, struggle to recognise the attributes and qualities that other tasters identify. Emphasising specific flavours and qualities clearly involves a process of tasting, identifying, labelling and valuing but discerning the flavours being tasted does not necessarily mean that each is experiencing the flavour in the same way. As Bennett reminds us, substances work on different bodies in different ways. Makers agree, however, that while they may individually identify particular characteristics in different ciders, they are all searching for those flavours and associate them with craft. Hence, normative frameworks of quality are enforced while the contents of such paradigms are being potentially disrupted.

The ways in which quality characteristics are abstractions of subjective corporeal experience has been further expounded by Coles' study of the production of taste 
profiles within the coffee industry. ${ }^{49} \mathrm{He}$ details an iterative process through which each taster individually details the flavours and aromas of each coffee and imprints them with signifiers, such as 'earthy' and 'peaty'. These definitions are then compared to the results of other tasters and place-based expectations of how a coffee from a particular region should taste. A collective profile of flavours is thereby created through the co-joining and flattening of tastes into specific industry-accepted characteristics. Coles further notes the ways in which this process trains the coffee-taster's palate in a manner not dissimilar to ways in which Latour observed perfumiers acquiring a 'nose' based on their continuous corporeal engagements. ${ }^{50}$ Or, returning to cider, that makers acquire a palate. But, like cider makers, coffee tasters do not just keep this abstracted knowledge to themselves. Rather the taste characteristics they identify are worked into marketing literature and sales brochures that, in turn, inform consumers' tasting experiences by indicating what flavours they should be able to identify in each coffee. Consumers' bodies are thus guided and trained via the bodies of industry experts: as Cole's concludes, 'to drink coffee is to drink a lot of bodies. ${ }^{51}$

This process maybe less explicit in craft cider but it is indicative of how prevalent the bodies of producers

49 Benjamin Coles, 'Ingesting Places: Embodied Geographies of Coffee', in Why We Eat, How We Eat: Contemporary Encounters Between Foods and Bodies, eds., Emma-Jayne Abbots and Anna Lavis (Aldershot: Ashgate, 2013), 255-70.

50 Bruno Latour, 'How to Talk About the Body?: The Normative Dimension of Science Studies', Body and Society, 10:2-3 (2004), 205-29.

51 Coles, Ingesting Places, 268. 
are, as well as also how the subjective sensorial experience of one can shape the corporeal encounters of others. Such making of taste, through a normative knowledge paradigm of signifiers and categories that is reproduced through further tasting and assessing, works to position those creating knowledge in a position of social authority or in the words of Bourdieu, as cultural intermediaries as they not only shape what can be tasted, but also whether that which is being tasted is in good taste. They thus become tastemakers in both senses of the word by inscribing their own embodied experience onto other bodies, and using their own subjective encounters to set the social parameters of what constitutes good taste.

\section{Conclusion}

As I have tried to show, the body and senses are deeply embedded within cider makers' normative frameworks both in the manner in which their own bodies, through the enactment of labour, are deemed to be a critical ingredient of a good-tasting cider, and in the sense that their own subjective embodied experience is a key mechanism for assessing and judging the quality of both their own and others' end products. It is only in tasting the drink that knowledges about what constitutes good taste can be made and remade, and the substances being tasted can be assessed against such frameworks.

I have written elsewhere that food is symbolic, political and economic, but also a material substance that we feel within our bodies, that stimulates our senses, produces embodied responses and invokes emotions, and 
I have made the argument that human and non-human bodies are commonly absented in their entirety in much Food Studies scholarship. ${ }^{52}$ Critical accounts of appellation protocols and terroir have tended to overlook both human and non-human bodies, focusing instead on the politicised processes through which celebrated foods become disembedded, abstracted, appropriated and commodified. ${ }^{53}$ Likewise, bodies are often rather ghostly entities in accounts of alternative and heritage foods, which have hinted at the bodily presence of producers but have rarely brought this to the analytical fore. Both these areas of scholarship have yielded significant insights into the cultural politics of artisan food and agri-capitalism and importantly drawn our attention to the political dynamics, economic inequities, and processes of alienation at play. Unpacking the factors motivating dominant scholastic trends has not been the purpose of my discussion. Nor is it my intention to diminish the value of this scholarship. Rather, I aim to highlight that, in turning an analytical 'blind-eye' to the body and the senses, a key part of the picture is being obscured. Seeking to understand the role that bodies, both human and non-human, play in the formation of normative frameworks of quality, by examining the processes through which sensory experiences, such as tasting, become abstracted, codified, and placed on a scale can, I hope to have indicated, be a productive

52 Abbots, The Agency of Eating, 155.

53 See West, Appellations and Indications of Origin, Terroir, and the Social Construction and Contestation of Place-Named Food and West, Artisanal Foods and the Cultural Economy for an overview of this literature. 
way through which the bodies in all their forms can be drawn into dialogue with political economy. It can also provide a route through which the multiplicities of, and interactions between, taste in both its corporeal and Bourdieusian forms can be interrogated.

Accounts of craft food and drinks are well placed to provide the material for such analyses. As West, drawing on Jackson and CONANX Group, observes, 'artisanal foods are often described as facilitating corporeal and sensorial reconnection ${ }^{54}$ and, although he and others have shown how these descriptions can lean towards problematic imaginings of romantic pastoralism, ${ }^{55}$ it is also evident that craft cider makers themselves draw connections between their human bodies, the substances they are tasting, their natural environments, and their socially produced and intuitive knowledge about what constitutes a quality cider. This process, in turn, constructs craft makers, their production practices, and their product as quality-laden, flavoursome and tasteful - and, most importantly, as craft. They do not create these normative frameworks in isolation, however, but in dialogue with 'others', both in form of appellation protocols and agri-capitalism. Thus, corporeal taste becomes a mechanism for defining social good taste and forging new forms of embodied political capital, with those producing such knowledges emerge as alternative tastemakers to regulatory paradigms of quality.

54 West, Artisanal Food and the Cultural Economy, 410.

${ }_{55}$ Nuno Domingos, Jose Sobral and Harry West, eds., Food Between the Country and the City: Changing Ethnographies of a Global Foodscape (London: Bloomsbury, 2014). 


\section{References}

Abbots, Emma-Jayne. The Agency of Eating: Mediation, Food and the Body. London: Bloomsbury, 2017.

Bennett, Jane. Vibrant Matter: A Political Ecology of Things. Durham, NC: Duke University Press, 2010.

Bourdieu, Pierre. Distinction: A Social Critique of the Judgement of Taste. New York and London: Routledge, 1984.

- The Logic of Practice. Translated by R. Nice. Bloomington, IN: Stanford University Press, 1990.

Bowen, Sarah and Kathryn De Master. 'New Rural Livelihoods or Museums of Production? Quality Food Initiatives in Practice.' Journal of Rural Studies 27, no. 1 (2011): 73-82.

Bowen, Sarah, and Ana Valenzuela Zapata. 'Geographical Indications, Terroir, and Socioeconomic and Ecological Sustainability: The Case of Tequila.' Journal of Rural Studies 25, no. 1 (2009): 108-19.

Butler, Judith. Bodies That Matter: On the Discursive Limits of "Sex". London: Routledge, 2003.

Carolan, Michael. Embodied Food Politics. Farnham: Ashgate, 2011. Cavanaugh, Jillian. 'Making Salami, Producing Bergamo: The Transformation of Value.' Ethnos 72, no. 2 (2007): 149-72.

Coles, Benjamin. 'Ingesting Places: Embodied Geographies of Coffee.' In Why We Eat, How We Eat: Contemporary Encounters Between Foods and Bodies, edited by Emma-Jayne Abbots and Anna Lavis, 255-70. Aldershot: Ashgate, 2013.

_. 'Placing Security: Food, Geographical Knowledge(s) and the Reproduction of Place(less-ness)'. In Careful Eating: The Embodied Entanglements of Food and Care, edited by EmmaJayne Abbots, Anna Lavis and Luci Attala, 151-72. Farnham: Ashgate, 2015.

_ 'The Shocking Materialities and Temporalities of Agricapitalism.' Gastronomica: The Journal of Critical Food Studies 16, no. 3 (2016): 5-11.

Csordas, Thomas. 'Introduction: The Body as Representation and Being-in-the-World.' In Embodiment and Experience: The Existential Ground of Culture and Self, edited by Thomas 
Csordas, 1-26. Cambridge: Cambridge University Press, 1994.

Department of Environment, Food and Rural Affairs. 'Protected Food Name: Traditional Welsh Cider.' https://www.gov.uk/ government/publications/protected-food-name-welsh-cider (accessed 11 November 2017).

Domingos, Nuno, Jose Sobral and Harry West, eds. Food Between the Country and the City: Changing Ethnographies of a Global Foodscape. London: Bloomsbury, 2014.

Goodman, David. 'Agro-food Studies in the 'Age of Ecology': Nature, Corporeality, Bio-Politics.' Sociologia Ruralis 39, no. 1 (1999): 17-38.

Hayes-Conroy, Allison and Jessica Hayes-Conroy. 'Taking Back Taste: Feminism, Food and Visceral Politics.' Gender, Place \& Culture: A Journal of Feminist Geography 15, no. 5 (2008): 461-73.

Hayes-Conroy, Jessica. Savoring Alternative Food: School Gardens, Healthy Eating and Visceral Difference. Abingdon: Routledge, 2014.

Jackson, Peter, and the CONANX Group. Food Words: Essays in Culinary Culture. London: Bloomsbury, 2013.

Kneafsey, Moya et al. Reconnecting Consumers, Producers and Food: Exploring Alternatives. Oxford: Berg, 2008.

Latour, Bruno. 'How to Talk about the Body?: The Normative Dimension of Science Studies.' Body and Society 10, no. 2-3 (2003): 205-29.

- Reassembling the Social: An Introduction to Actor Network Theory. Oxford: Oxford University Press, 2005.

Marx, Karl. Capital: An Abridged Edition. Oxford: Oxford University Press, 1995(1867).

Matthews, Julian and Jennifer Smith Maguire. 'Introduction: Thinking with Cultural Intermediaries.' In The Cultural Intermediaries Reader, edited by Jennifer Smith Maguire and Julian Matthews, 1-12. London: Sage, 2014.

Mintz, Sidney. 'Food at Moderate Speeds.' In Fast Food/Slow Food: The Cultural Economy of the Global Food System, edited by Richard Wilk, 3-11. Lanham: Altamira, 2006. 
Mol, Anne-Marie. 'I Eat an Apple: On Theorizing Subjectivities' Subjectivity 22 (2008): 28-37.

Paxson, Heather. The Life of Cheese: Crafting Food and Value in America. Berkeley, CA: University of California Press, 2013. Petrini, Carlo. Slow Food: The Case for Taste. New York: Columbia University Press, 2001.

Probyn, Elspeth. Carnal Appetites: FoodSexIdentities, London and New York: Routledge, 2000.

Ritzer, George. McDonaldization: The Reader. Los Angeles, CA: Pine Forge Press, 2010.

Scheper-Hughes, Nancy and Margaret Lock. 'The Mindful Body: A Prolegomenon to Future Work in Medical Anthropology'. Medical Anthropology Quarterly 1, no. 1 (1987) 6-41. Sutton, David. Remembrance of Repasts: An Anthropology of Food and Memory. Oxford: Berg, 2001.

Turner, Brian. The Body and Society: Explorations in Social Theory, $2^{\text {nd }}$ edition. London: Sage Publications, 1996.

West, Harry. 'Appellations and Indications of Origin, Terroir, and the Social Construction and Contestation of PlaceNamed Foods.' In The Handbook of Food Research, edited by Anee Murcott, Warren Belasco and Peter Jackson, 209-28. London: Bloomsbury, 2013.

- 'Artisanal Foods and the Cultural Economy: Perspectives on Craft, Heritage, Authenticity and Reconnection.' In Handbook of Food and Anthropology, edited by Jakob Klein and James Watson, 406-34. London: Bloomsbury, 2016.

West, Harry, and Nuno Domingos. 'Gourmandizing Poverty Food: The Serpa Cheese Slow Food Presidium.' Journal of Agrarian Change 12, no. 1 (2012): 120-43.

Wright, Jan, and Valerie Harwood, eds. Biopolitics and the 'Obesity Epidemic': Governing Bodies. New York: Routledge, 2009. 